\title{
Reabilitação estética anterior através de coroas metalocerâmicas: relato de caso
}

Atualmente, a busca pela boa aparência estética reflete grande importância na aceitação de um sorriso esteticamente agradável. De acordo com a Organização Mundial da Saúde (OMS) a cárie dental é a segunda doença mais comum do mundo, se não for tratada pode acometer a destruição total do elemento dentário, o que gera comprometimento estético e funcional quando afeta dentes anteriores. Contundo, existem várias formas de reabilitação em casos de destruição coronária, como restaurações em resina composta sobre o pino intra radicular e coroas protéticas, sendo a coroa a de principal escolha para perdas coronárias extensas. Assim, o objetivo deste estudo foi relatar um caso ocorrido na clínica odontológica integrada da faculdade IMMES, o qual se destaca a reabilitação estética de dentes anteriores por meio de coroas do tipo metalocerâmica. No qual a metodologia utilizada foi o relato de caso, concluindo que diante do caso clinico relatado, certificamos a gama de desafios em reestabelecer a estética e a funcionalidade de dentes anteriores, devendo individualizar cada caso conforme as necessidades de cada paciente. No caso em questão, a paciente relatou satisfação estética e funcional quanto ao resultado final da reabilitação.

\section{Anterior aesthetic rehabilitation through metalloceramic crowns: case report}

\begin{abstract}
Today, the pursuit of good aesthetic appearance reflects great importance in accepting an aesthetically pleasing smile. According to the World Health Organization (WHO) dental caries is the second most common disease in the world, if left untreated it can affect the total destruction of the dental element, which generates aesthetic and functional impairment when affecting anterior teeth. However, there are several forms of rehabilitation in cases of coronary destruction, such as composite resin restorations on the intra-root pin and prosthetic crowns, the crown being the main choice for extensive coronary loss. Thus, the aim of this study was to report a case that occurred in the integrated dental clinic of IMMES College, which highlights the aesthetic rehabilitation of anterior teeth by means of metal-ceramic crowns. In which the methodology used was the case report, concluding that given the reported clinical case, we certify the range of challenges in reestablishing the aesthetics and functionality of anterior teeth, and should individualize each case according to the needs of each patient. In this case, the patient reported aesthetic and functional satisfaction regarding the final outcome of the rehabilitation.
\end{abstract}

Keywords: Coronary destruction; Metaloceramic crown; Case report.

Topic: Clínica Odontológica

Reviewed anonymously in the process of blind peer.
Received: 21/06/2019

Approved: 11/09/2019
Karla Gabrielly Azevedo Lima (iD)

Instituto Macapaense de Ensino Superior, Brasil

http://lattes.cnpq.br/0386761755856294

http://orcid.org/0000-0001-7406-8671

carla-gab@hotmail.com

Brenda Matsunaga Laurindo (D)

Instituto Macapaense de Ensino Superior, Brasil

http://lattes.cnpq.br/6687511503501079

http://orcid.org/0000-0002-3431-8493

brenda.matsunaga@hotmail.com
Referencing this:

LIMA, K. G. A.; LAURINDO, B. M.. Reabilitação estética anterior através de coroas metalocerâmicas: relato de caso. Scire Salutis, v.9, n.3, p.16-21, 2019. DOI: http://doi.org/10.6008/CBPC2236$\underline{9600.2019 .003 .0003}$ 


\section{INTRODUÇÃO}

A busca pela boa aparência estética reflete grande importância na aceitação de um sorriso esteticamente agradável, desse modo a busca por tratamentos estéticos na odontologia estimulam a procura por alternativas de tratamento, se baseando em reproduzir dentes com proporções adequada que consigam estabelecer um equilíbrio com os tecidos gengivais (JORGE et al., 2019).

De acordo com a Organização Mundial da Saúde (OMS) a cárie dental é a segunda doença mais comum do mundo, se não for tratada pode acometer a destruição total do elemento dentário, o que gera comprometimento estético quando afeta dentes anteriores. Contundo, os avanços da odontologia permitem várias formas de reabilitação em casos de destruição coronária extensas, apresentando envolvimento endodôntico, o emprego de pinos intra-radiculares associada a resina composta ou coroas protéticas são considerados uma boa conduta terapêutica pra destruição coronárias extensas em dentes anteriores (SANTANA et al., 2010).

As resinas compostas são materiais muito utilizados para restaurações estéticas, entretanto representam um grande desafio por apresentar constantemente fraturas e reincidias de cárie (JORGE et al., 2019). As cerâmicas odontológicas vêm de destacando cada dia mais na odontologia, por apresentarem propriedades semelhantes ás dos dentes naturais, estabilidade de cor, biocompatibilidade e resistência (JORGE et al., 2019).

\section{METODOLOGIA}

\section{Caso Clínico}

O paciente RPP, 25 anos, gênero feminino, leucoderma, compareceu ao atendimento da clínica odontológica do IMMES (Instituto Macapaense do Melhor Ensino Superior), queixando-se de dor no elemento 12 e 21 e insatisfação com a estética dos elementos 11,12 e 21 (Figura1).

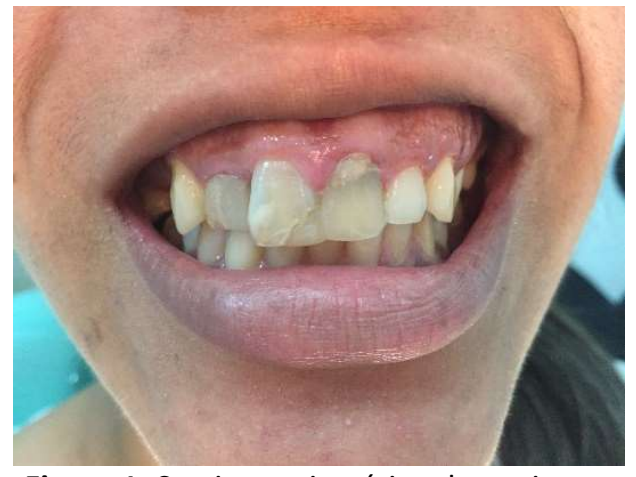

Figura 1: Sorriso antiestético do paciente.

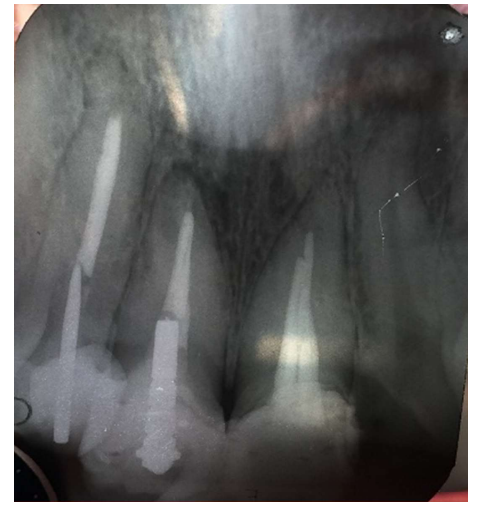

Figura 2: Exame radiográfico inicial.

Foi realizado exame clínico, no qual foi observado escurecimento nos elementos 11 , 12 e 21 , a presença de restauração mediana de classe vl em resina composta com fenda marginal no elemento 11, extensa restauração insatisfatória de resina composta no elemento 21, infiltração marginal nos elementos 12 e 21 e a presença de edema na papila incisa. No exame radiográfico, foi verificado que o tratamento 
endodôntico dos elementos 11, 12 e 21 estavam insatisfatórios (Figura 2). Foi realizado a retirada do pino intra-radicular de metal do elemento 11 com o auxílio de um ultrassom e na mesma sessão foi feita uma restauração provisória com resina composta na cor A 3,5 (Figura 3).

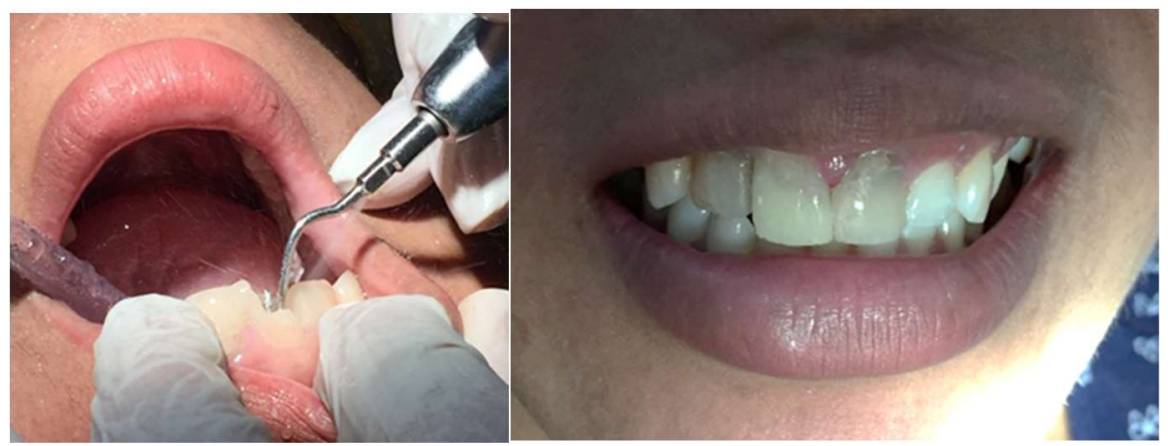

Figura 3: Retirado do pino intra-radicular e restauração provisória com resina composta.

Foi removido do elemento 12 uma haste de broca utilizada como pino com auxílio de um ultrassom na mesma sessão foi feita uma restauração com resina composta na cor A 3,5 (Figura 4).

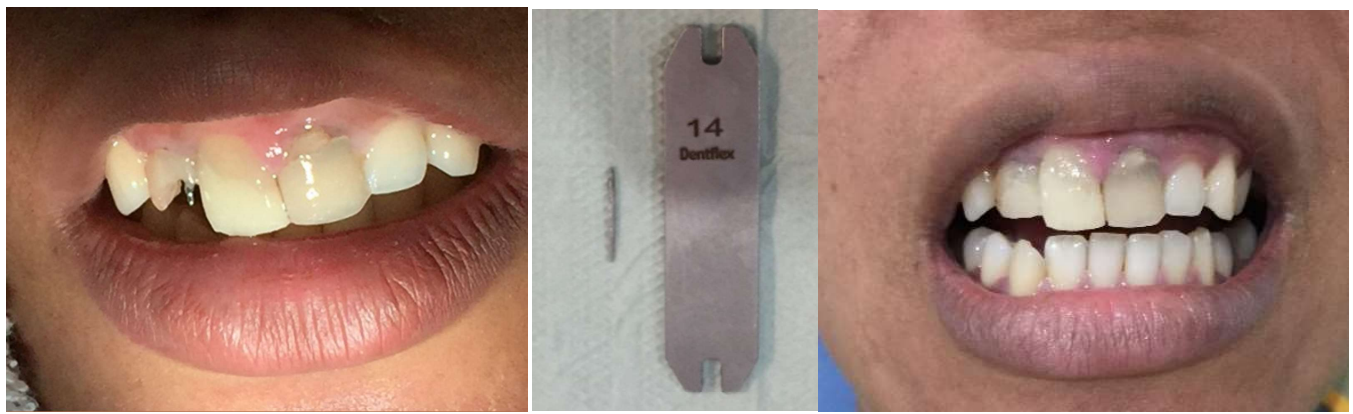

Figura 4: Retirado da haste de broca e restauração provisória com resina composta.

Foi realizado o retratamento endodôntico nos elementos 11, 12 e 21 e a cimentação de pinos intraradicular de fibra de vidro ( Figura 5 e 6 ).

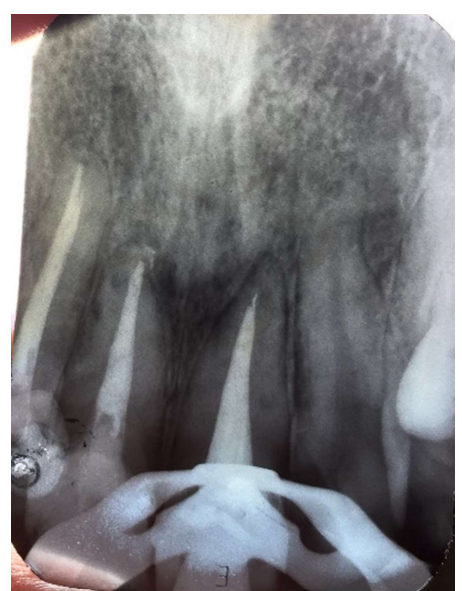

Figura 5: Rx final dos retratamentos endodônticos.

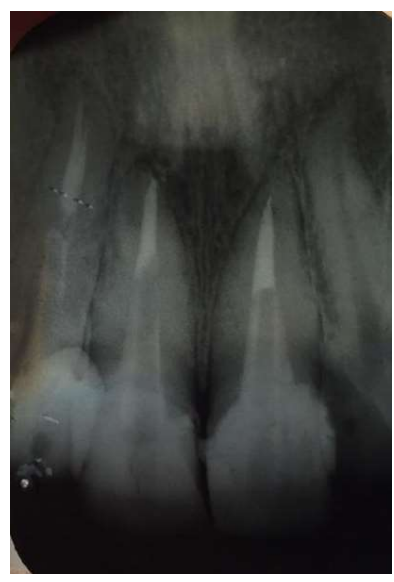

Figura 6: Rx com os pinos de fibra de vidro cimentados.

Foi realizado o preparo do tipo chanfro largo com a ponta diamantada \#3227 nos três elementos e o afastamento gengival com o fio retrator \#00 (Figura 7). 


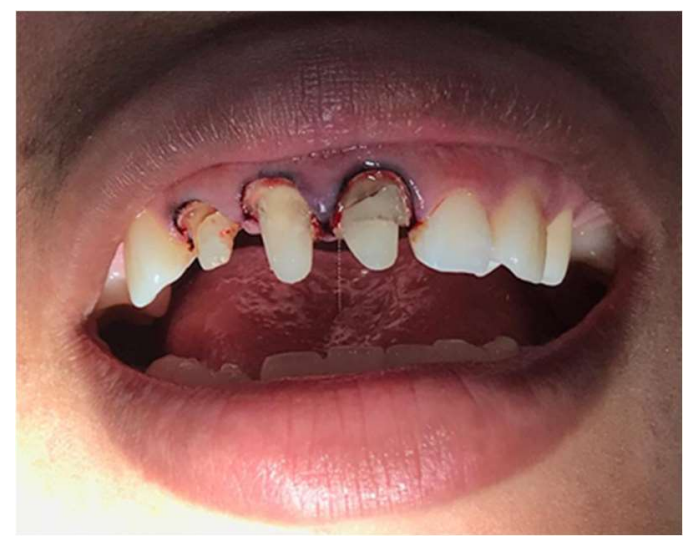

Figura 7: Realização dos preparos.

A moldagem foi executada com silicone de condensação e o vazamento do gesso especial imediato em seguida foi confeccionado os provisórios (Figura 8 e 9).

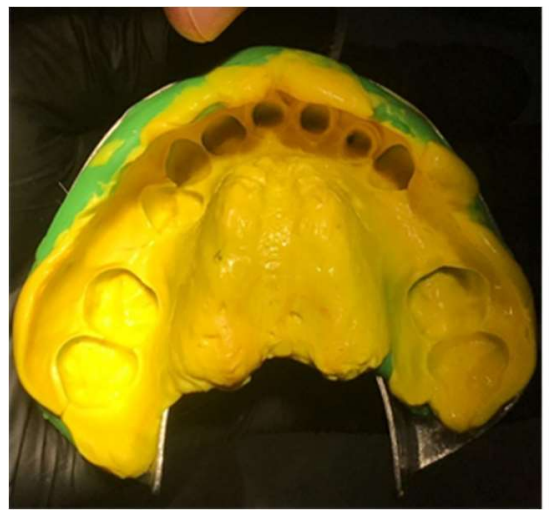

Figura 8: Moldagem com silicone de condensação.

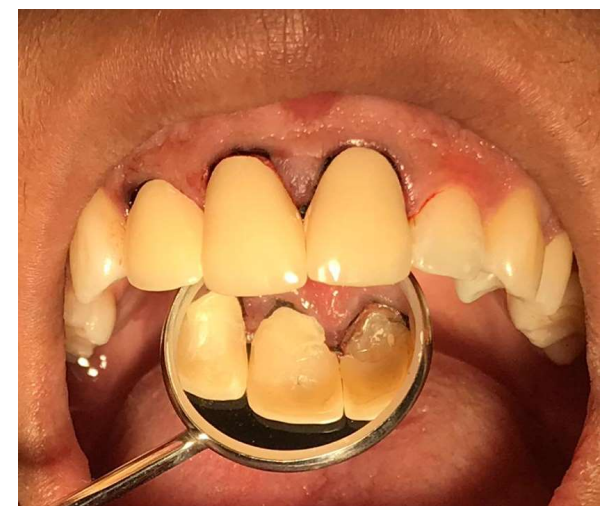

Figura 9: Prova com provisórios.

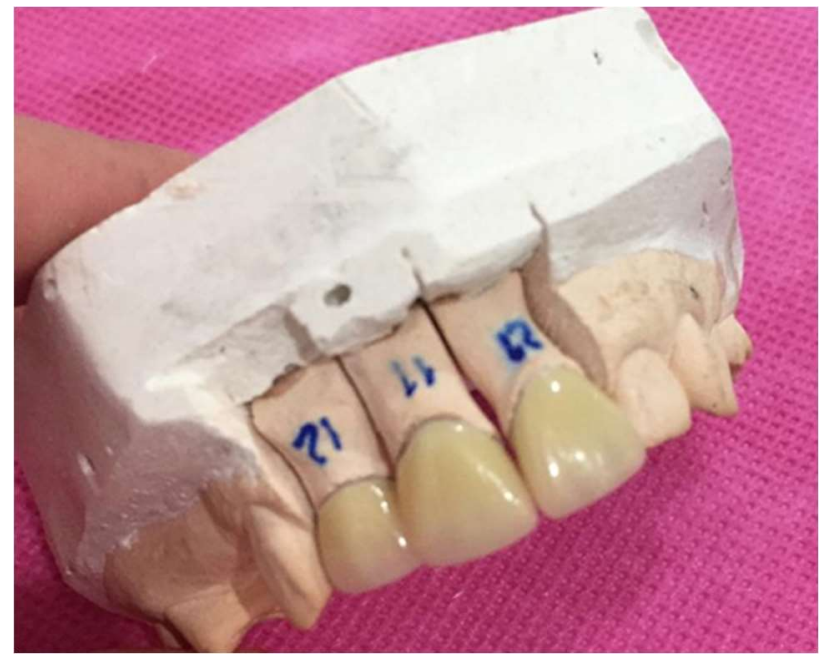

Figura 10: Coroas do tipo metalocerâmicas na cor A 3,5 prontas para cimentação.

Foi escolhido um cimento translúcido e realizado a preparação das peças de metalocerâmicas com condicionamento das peças com ácido clorídrico por 30 segundos, lavados com água e secas com jatos de ar. Após o preparo das peças, foi realizada a preparação dos dentes com profilaxia com pedra pomes e água, condicionamento ácido fosfórico a 37\% durante 15 segundos(Figura 11), lavados e secos. Em seguida foi aplicado o adesivo (Figura 12) e foi fotopolimerizado por 40 segundos. Foi utilizado o cimento resinoso o qual foi removido os excessos e fotopolimerizado por 20 segundos em cada face. 


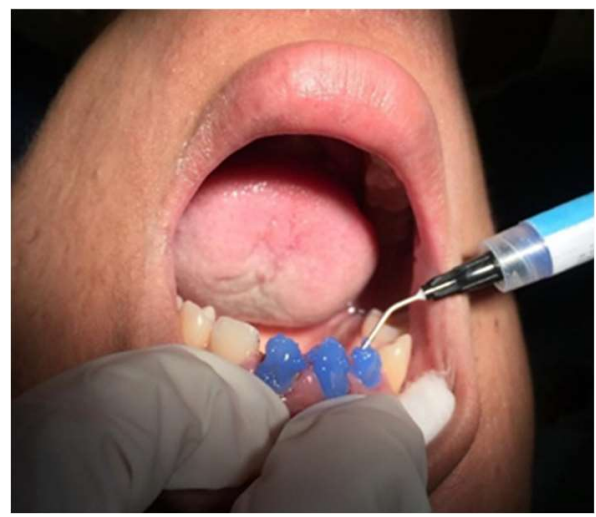

Figura 11: Condicionamento ácido.

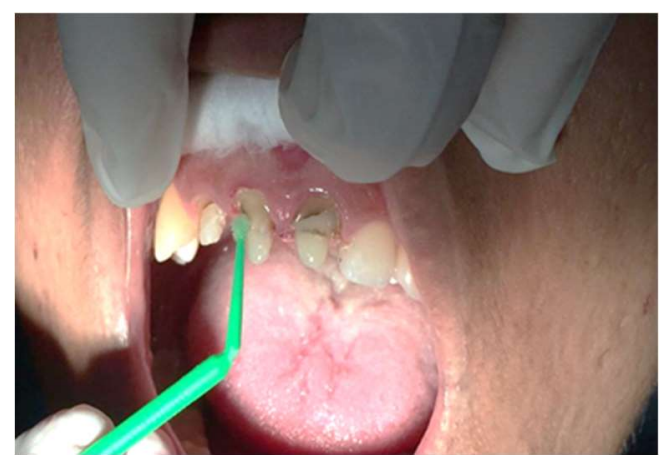

Figura 12: Aplicação do adesivo.

Na sequência foi realizado o ajuste oclusal. O resultado final (Figura 13) estético e funcional foi aproado pelo paciente e pelos profissionais envolvidos.

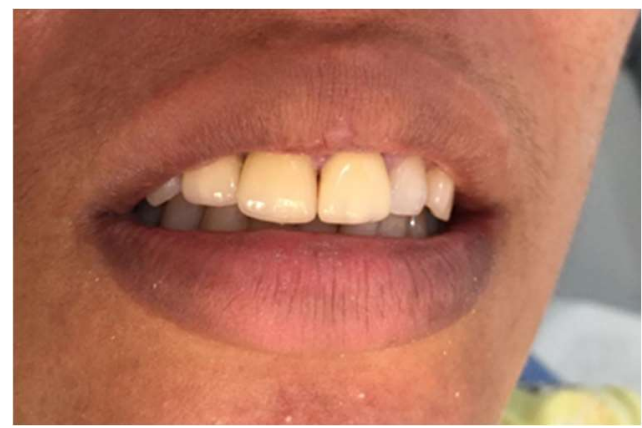

Figura 13: Resultado Final.

\section{RESULTADOS E DISCUSSÃO}

No mercado existem diversos tipos de materiais para prótese fixa, a paciente optou pela escolha da prótese fixa de metalocerâmica onde em sua camada superficial é composta de cerâmica e seu interior é composta por metal resistente. $O$ sucesso de uma prótese fixa está relacionada diretamente com a qualidade do preparo coronário, visando um preparo que acompanhe a anatomia dental do paciente (RIBEIRO et al., 2005). O retratamento endodôntico é considerada a primeira opção quando o tratamento endodôntico falha, por ser considerado uma abordagem conservadora comparada a exodontia (ROCHA et al., 2016).

\section{CONCLUSÕES}

Diante do caso clinico relatado, certificamos a gama de desafios em reestabelecer a estética e a funcionalidade de dentes anteriores, devendo individualizar cada caso conforme as necessidades de cada paciente. No caso em questão, a paciente relatou satisfação estética e funcional quanto ao resultado final da reabilitação.

\section{REFERÊNCIAS}

JORGE, C. F.; BITENCOURT, S. B.; MAZZA, L. C.; CAMPANER, M. C.; BRUNETTO, J. L.; SANTOS, D. M.; PESQUEIRA, A. A.. O desafio do restabelecimento de um sorriso antiestético por meio de prótese fixa metal-free. Arch Health Invest, v.8, n.1, p.6-12, 2019. DOI:

http://dx.doi.org/10.21270/archi.v8i1.3236
RIBEIRO, C. F.; RODE, S. M.; NEVES, A. C.; FILHO, A. L.. Formas e características da infraestrutura metálica das restaurações metalocerâmicas convencionais, Revista Biociência, v.11, n.1-2, p.77-83, 2005. 
ROCHA, M. P.; SILVA, R. V.; SILVA, L. R. M.; ROCHA, T. C. M.; BRITO, A. M.; PEREIRA, R. P.. Retratamento endodôntico não cirúrgico: relato de caso. Rev. Odontol. Univ. Cid. São Paulo, São Paulo, v.28, n.3, p.270-276, 2016.
SANTANA, I. L.; CARMO, C. D. S.; GALVÃO, L. C. C.; PEREIRA, A. F. V.. Reconstrução estética utilizando prótese adesiva como forma de reabilitação oral em serviço público, Odontol. Clín. Cient., v.9, n.3, p.271-273, 2010.

A CBPC - Companhia Brasileira de Produção Científica (CNPJ: 11.221.422/0001-03) detém os direitos materiais desta publicação. Os direitos referem-se à publicação do trabalho em qualquer parte do mundo, incluindo os direitos às renovações, expansões e disseminações da contribuição, bem como outros direitos subsidiários. Todos os trabalhos publicados eletronicamente poderão posteriormente ser publicados em coletâneas impressas sob coordenação da Sustenere Publishing, da Companhia Brasileira de Produção Científica e seus parceiros autorizados. Os (as) autores (as) preservam os direitos autorais, mas não têm permissão para a publicação da contribuição em outro meio, impresso ou digital, em português ou em tradução. 